\title{
Correction to: Emergency endovascular treatments for delayed hemorrhage after pancreaticobiliary surgery: indications, outcomes, and follow-up of a retrospective cohort
}

Riccardo Mugliaa ${ }^{1,2}$ - Ezio Lanza ${ }^{1} \cdot$ Dario Poretti $^{1} \cdot$ Felice D'Antuono ${ }^{1} \cdot$ Nicolò Gennaro $^{1,2} \cdot$ Francesca Gavazzi $^{1}$. Alessandro Zerbi ${ }^{1,2} \cdot$ Arturo Chiti $^{1,2} \cdot$ Vittorio Pedicini $^{1}$

Published online: 9 September 2020

(c) Springer Science+Business Media, LLC, part of Springer Nature 2020

Correction to: Abdominal Radiology

https://doi.org/10.1007/s00261-020-02480-z

The original version of this article has an error in the affiliations of all the authors. The authors affiliations are corrected.

Publisher's Note Springer Nature remains neutral with regard to jurisdictional claims in published maps and institutional affiliations.

The original article can be found online at https://doi.org/10.1007/ s00261-020-02480-z.

Riccardo Muglia

riccardo.muglia@humanitas.it

1 Humanitas Clinical and Research Center - IRCCS, via Manzoni 56, 20089 Rozzano, Milano, Italy

2 Department of Biomedical Sciences, Humanitas University, Via Rita Levi Montalcini 4, 20090 Pieve Emanuele, Milan, Italy 